\title{
The Acculturation Experiences of Elite Rugby Union Coaches
}

\author{
Andrew J.A. Hall \\ Hong Kong Rugby Union and Edinburgh Napier University \\ Leigh W. Jones \\ Hong Kong Rugby Union
}

\author{
Cedric English \\ Edinburgh Napier University \\ Russell J.J. Martindale \\ Edinburgh Napier University
}

\begin{abstract}
Currently, little is known about how elite coaches acculturate and how they manage their acculturation environment. This study examines the acculturation experiences of elite rugby union coaches and their management of multicultural squads. Five male elite coaches participated in the research. Each of the five coaches arguably fit a "best of the best" criterion, boasting between them multiple European and U.K. domestic championships as well as multiple Super Rugby titles with similar accomplishments at the international level across 15- and seven-a-side. Inductive thematic analysis of semistructured interview data revealed three emerging themes: (a) proactively managing personal acculturation, (b) proactively managing player acculturation, and (c) critical components of a team culture. Implications for coaches managing their own acculturation experience and their respective acculturation environments are discussed.
\end{abstract}

Keywords: challenges, coach migration, high performance, transnational

In 2013, an estimated 214 million individuals were considered migrants — one in 33 people worldwide_and of those was a growing number of transnational elite sport professionals, including coaches, who may have migrated between and within nations to further their athletic careers (Ryba, Schinke, Stambulova, \& Elbe, 2018). In the sporting context, migrants may be categorized based on the motivations underpinning their movement (Orlowski, Wicker, \& Breuer, 2016). For the premise of this research, the coach migrants are referred to as voluntary sojourners who leave by choice, relocating on a timeline basis for a specific purpose, that is, a fixed-term contract for a specific role (Schwartz, Unger, Zamboanga, \& Szapocznik, 2010). As an indication of the prevalence of sporting migration, over the last 30 years a significant number of Chinese coaches have moved to Australia, augmenting the host's Olympic diving teams (Tao, Rynne, \& Mallett, 2019) with similar movements of Russian gymnastic coaches expatriating to New Zealand (Kerr \& Obel, 2018).

Relocating can prove stressful with the newcomer facing numerous potential challenges, for example, learning a new culture and potentially a new language as well as coping with being away from the support of family and friends (Schinke, Yukelson, Bartolacci, Battochio, \& Johnstone, 2011). Such stressors are often magnified in sport where individuals may also experience potential change in their coaching demands, different coach-athlete relationship dynamics, and even changes in how to behave and/or communicate within the new environment (Schinke et al., 2011; Schinke, McGannon, Battochio, \& Wells, 2013). For instance, former Soviet Union gymnastic coaches identified a number of sociocultural challenges in their move to New Zealand, such as the perceived poor work ethic from the performers, the overly active role of performer parents, and the ability of performers to accept

Hall and Jones are with the Hong Kong Rugby Union, Hong Kong, Hong Kong. Hall, English, and Martindale are with the Edinburgh Napier University, Edinburgh, critical feedback (Kerr \& Moore, 2015). A failure to adapt to these dramatic changes can lead to maladaptive states of "culture shock," (Schinke, Blodgett, McGannon, \& Ge, 2016a) resulting in a sense of isolation and being overwhelmed. Evidence of this was reported among immigrant elite coaches in Canada who reported negative effects of their relocation as they felt at times disrespected, mocked, and deeply dissatisfied by the standards of training (Schinke, McGannon, Yukelson, Cummings, \& Parro, 2015). The increase in global mobility of sports professionals has also seen a requirement for coaches and support staff to not only manage their own relocation challenges but also hone their cultural intelligence-that is, the ability to function effectively in a culturally diverse setting (Earley \& Ang, 2003). As an example, European basketball coaches emphasized the important balance between the individualistic views of immigrant players with the contrasting collectivist position of "local" players with goal setting becoming a central premise factor in unifying the conflicting viewpoints (Khomutova, 2016).

The process that any newcomer-including sporting migrantsgoes through to psychologically adapt to the habits and practices common to the host country's culture is called acculturation. According to Berry (1997) — a recognized scholastic leader in this domain (Ward \& Kus, 2012) - acculturation is a lengthy continual process and describes "what happens to individuals who have developed in one cultural context when they attempt to reestablish their lives in another" (Berry, 1997, p. 5). Acculturation research within sport is a relatively new topic, but considering the increasing number of performers relocating due to the globalization of sport with the associated acculturative experiences of coaches (and athletes) impacting performance and well-being (Schinke et al., 2015), it is clear why study of acculturation has begun to increase within sport psychology (Khomutova, 2016; Ryba, Stambulova, Ronkainen, Bundgaard, \& Selänne, 2015). For example, Schinke et al. (2015) examined 10 immigrant elite sport coaches in Canada, exploring aspects impacting their respective acculturating experiences, namely, 
training standards, commitment levels, athlete respect and coach status, and credential recognition. Research into the acculturation experiences of professional basketball coaches in central Europe revealed three themes around value differences and playing styles, working with Black players, and the formation of ethnic subgroups (Khomutova, 2016) with Schinke et al. (2013) highlighting the need for coaches to bridge the gap of world views by balancing positive perceptions of the host context with what can be learned from the immigrant individual's culture. Examples of this favored shared approach alluded to earlier may include strategies such as language learning exchanges or understanding and celebrating cultural festivities among team members (Schinke et al., 2013; Schinke \& McGannon, 2014). Other shared strategies might extend beyond the coach and include senior players reinforcing the expected behaviors or work ethic of the newcomer, for example (Ronkainen, Khomutova, \& Ryba, 2019). Whether involved directly or indirectly, the coach is crucial for driving these approaches.

\section{Theoretical Framework}

Acculturation has existed for millennia with contemporary research interest growing out of concern for the effects of European domination of indigenous peoples (Berry, 2005). Over the last three decades, John Berry's (1997) Framework for Acculturation Research has been widely acclaimed (Schwartz et al., 2010; Ward \& Kus, 2012) and is based on his bidimensional acculturation model that posits that immigrants and individual groups are confronted with two main issues in the acculturation process and vacillate between heritage-culture retention and receivingculture acquisition. (Berry, 1997). In attempting to synthesize the multifaceted processes of acculturation, Berry's (1997) framework (Figure 1) illustrates the main factors that influence an individual's acculturative experiences, combining both structural and process features and guiding research through inputs, outcomes, and moderating factors.

On the left side of Figure 1 are "group-level variables," described as predominantly situational, that is, they are dependent on the interaction between individuals within a group (Berry, 1997), and to the right are "individual-level variables" referring to individual factors. Both group and individual variables are essential elements when studying psychological acculturation (Berry, 1997). The right-hand upper block refers to features that exist prior to acculturation with the lower block containing elements that arise during the process of acculturation (Berry, 1997). The center of the framework represents the flow of the acculturation process over time, beginning with the initial contact with the host/dominant culture, followed by an assessment of that experience (with associated stresses) and subsequent strategies used, assessment of those strategies, and subsequent adaptation, that is, long-term outcomes (Berry, 1997).

In terms of the strategies used as part of the moderating factors during acculturation, Berry (1997) provides additional detail highlighting four approaches. The first is assimilation wherein individuals discard their cultural identity and seek daily interaction

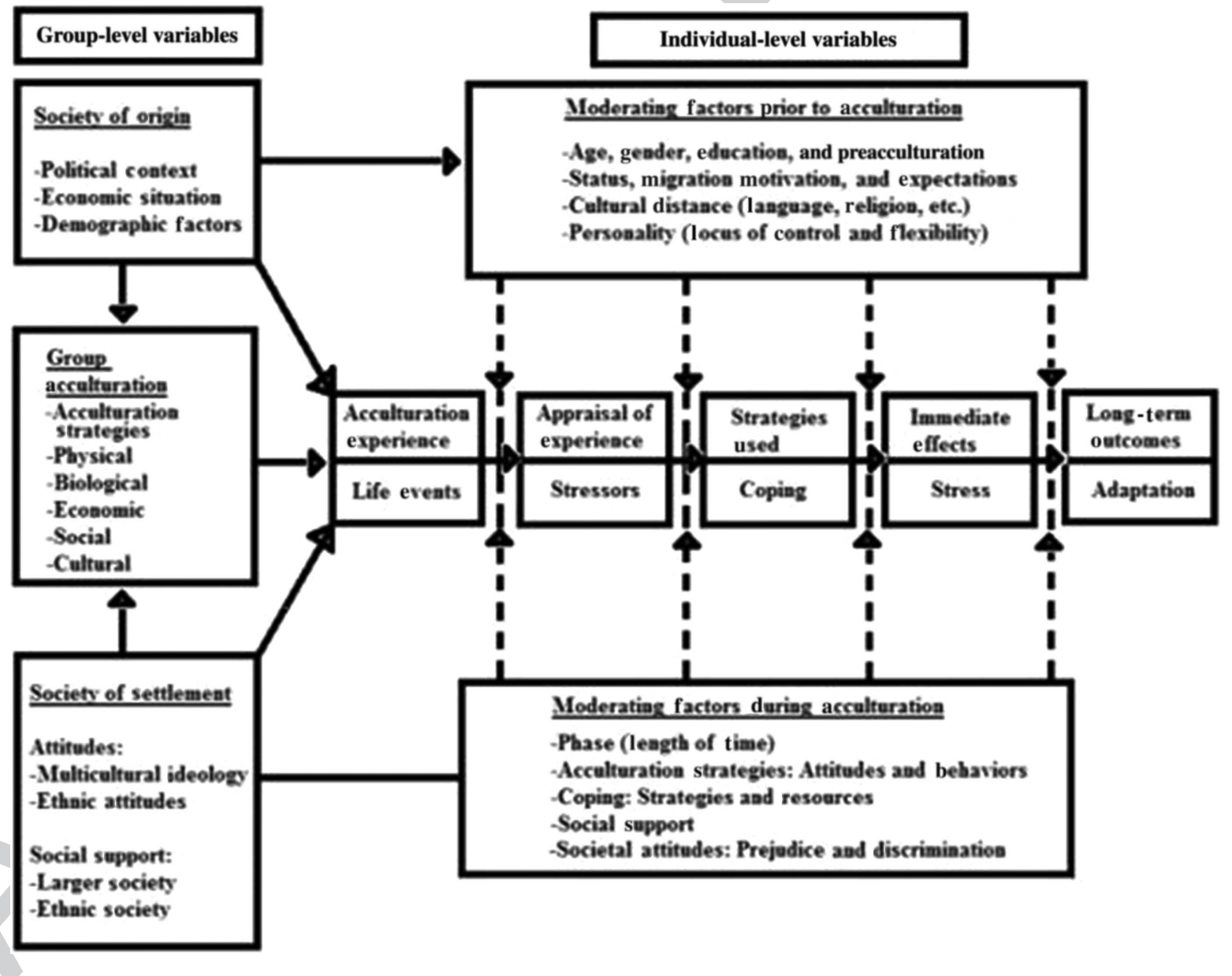

Figure 1 - Berry's (1997) framework for acculturation research. 
with other cultures. Second, separation occurs when an individual places value on maintaining their original culture and avoids contact and interaction with others. Third, and most desirable, is integration, which sees an interest in the individual in maintaining their original culture and spending time interacting with other groups. Integration is the more psychosocially adaptative strategy wherein acculturative stress is minimized (Berry, 2005) and wellbeing and optimal adjustment are maximized (Schinke, McGannon, \& Smith, 2016c). Finally, marginalization occurs when both original and receiving cultures are rejected and, as such, causes the greatest acculturative stress (Berry, 2005). The strategy adopted by an individual will determine the extent to which they adapt to their new environment. These adaptations may or may not be positive and include psychological adaptation (psychological and physical well-being) and sociocultural adaptation (how well the acculturating individual manages daily life in the new cultural context; Berry, 2005). Factors assisting in an individual's adaptation, as indicated within moderating factors during acculturation, include social support and positive intergroup attitudes, with the latter indicating how acculturation should be a shared process of immigrants and hosts working through differences and how both groups move between each other's cultural practices (Verkuyten, 2005).

Given the predominance of Berry's (1997) work in bilateral acculturation research and the need for further acculturation studies in elite sport coaching, Berry's framework provides an ideal lens to view both coach acculturation processes and those of the acculturation environment. The purpose of this article, therefore, using Berry's (1997) framework, is to advance the knowledge of acculturation within elite sport by answering three key questions. First, furthering the limited work examining coach perspectives (Borges, Rosado, de Oliveira, \& Freitas, 2015; Kerr \& Obel, 2018; Schinke et al., 2015), what are the personal acculturation strategies adopted by elite coaches? Second, what are the associated challenges with acculturation? Third, in examining the paucity in understanding of the acculturation environment (Ryba et al., 2018; Schinke et al., 2013), how does the host environment support players coming into a team?

\section{Method}

\section{Participants}

The sample consisted of five male elite rugby union coaches-four of whom, at the time of the interviews, were head coach at either a Guinness Pro 14 team (played in Wales, Ireland, Scotland, and Italy) or a Gallagher Premiership Club (played in England) with one participant the head coach of a World Sevens Series team. The coaches were purposefully chosen with each of the coaches coaching outside of their country of origin and having had experienced repeated successes in managing multicultural squads. To maintain participant anonymity the coaches' demographics are broadly presented in Table 1 . Furthermore, any references made within the results to teams or individuals that could potentially identify the participants were removed or replaced with pseudonyms.

\section{Design}

With the aim of generating meaningful and practical knowledge, a pragmatic research philosophy was used to frame this study (Giacobbi, Poczwardowski, \& Hager, 2005). The pragmatic approach sees the researcher as a part of the research process and a coconstructor of knowledge (Giacobbi et al., 2005). The first author's close connection with the research subject as a current professional coach was, therefore, seen as a critical element for interpreting participant responses as part of the data analysis. As an additional influence, the first author's close connection afforded access to the often inaccessible world of elite sport.

A qualitative design was selected to gain a rich and "real world" insight into the management of multicultural squads through the eyes of elite head coaches as well as their personal acculturation experiences (Creswell, Hanson, Clark Plano, \& Morales, 2007). Such a design allowed participants to provide a much needed in-depth and detailed understanding of acculturation in elite sport (Schinke et al., 2016c). Due to the nature of the research aims and given the previously reported overreliance on quantitative analysis into acculturation (Chirkov, 2009), a semistructured interview procedure was chosen. Although typically a pragmatic philosophy would be associated with a mixed-methods approach, a combination of both qualitative and quantitative (Giacobbi et al., 2005), it was decided that due to the importance of exploring the coaches' perceptions, a qualitative method was most suitable. The nature of the interview structure, in addition to the rapport created by the researcher's partial insider status, leant itself to a level of conversational freedom enabling emerging themes to be explored (Weller, 2017).

The five participants were interviewed across six key questions (see Table 2). Additional exploratory questions were used to prompt the participants to expand their answers, providing further depth to their responses (Moser \& Korstjens, 2018).

\section{Procedure}

Prior to the participants being identified for interview, ethical approval was gained. All participants were recruited via personal e-mail and, in keeping with ethical considerations as suggested by Willig (2008), informed consent was obtained to take part in a oneon-one interview with details of the voluntary nature of their participation explained.

With the global outbreak of the COVID-19 virus at the time of the research, restricting all travel and social meetings, all five interviews were conducted through Skype. The use of such video

\section{Table 1 Coach Demographics}

\begin{tabular}{lcccc}
\hline & Age & Nationality & Tenure in current role & Professional coaching experience \\
\hline Coach 1 & 50 & English & 4 years & 19 years \\
Coach 2 & 52 & Irish & 10 years & 19 years \\
Coach 3 & 47 & Welsh & 4 years & 9 years \\
Coach 4 & 56 & New Zealander & 3 years & 21 years \\
Coach 5 & 49 & English & 3 years & 15 years \\
& Mean $=50.8(\sigma=3.42)$ & & Mean $=4.8(\sigma=2.95)$ & Mean $=16.6(\sigma=4.77)$ \\
\hline
\end{tabular}


Table 2 Interview Questions Posed to the Elite Coaches

Interview questions

1. How influential do you view the team culture of the teams you coach?

2. When you arrived in your current position how did you go about creating "your way" regarding the culture?

3. How have you managed/do you manage the multicultural nature of the squads you've coached/coach?

4. What strategies are in place/have you previously put in place for the integration of new players and foreign players?

5 . What were some of the challenges you experienced as a foreign coach?

6. If you were going to drive the development of an emerging/young rugby nation, how would you approach the task?

Table 3 Six Phases of Thematic Analysis (Braun \& Clarke, 2006)

\begin{tabular}{l} 
Phase \\
\hline 1. Familiarization with data \\
2. Generating initial codes \\
3. Searching for themes \\
4. Reviewing themes \\
5. Defining and naming themes \\
6. Producing the report \\
\hline
\end{tabular}

conferencing technology has increased in qualitative research over recent years and is a valid method to obtain data when face-to-face opportunities are not possible or practical (Schinke et al., 2016c). Each interview lasted between 45 and 80 min and was recorded on a digital recording device.

\section{Data Analysis}

Once the interviews were complete, the first author transcribed them, enhancing his familiarity with the data and helping to establish an early set of themes (Rapely, 2011). Verbatim transcriptions then went through a process of reflexive inductive thematic analysis (Braun \& Clarke, 2019). This type of analysis, in line with pragmatic research (Giacobbi et al., 2005), places an importance on the researcher's role in knowledge production (Braun \& Clarke, 2019). The steps of analysis are shown in Table 3 and follow the six-stage process as outlined by previous work of Braun and Clarke (2006). For example, following the transcriptions, the second stage of analysis involved creating codes across the entire data set and then grouping the data into themes. The themes were then refined and examined for coherent patterns of meaning,. Then the entire data set was reviewed independently by the first author and two of his coauthors, ensuring a consistent message across all themes. Finally, clear definitions of each theme were generated, ensuring each concisely gave the reader clarity through the overall story. Following this process, as shown in Table 4, two higher order themes were generated, each with a group of associated lower order themes, all based on quotes or "tags" from the data (Cote, Salmela, Baria, \& Russell, 1993).

\section{Trustworthiness and Credibility}

First, the very nature of the participants' experiences and success, as outlined previously, provided an implicit level of credibility to the findings, leading to "best practice" in seeking solutions to the applied challenge of elite coach acculturation and the management of the acculturation environment as well as multicultural squads (Giacobbi et al., 2005). In addition, more explicit tools were used to
Table 4 Higher and Lower Order Themes

\begin{tabular}{ll}
\hline Higher order themes & Lower order themes \\
\hline $\begin{array}{l}\text { Proactively managing } \\
\text { personal acculturation }\end{array}$ & $\begin{array}{l}\text { 1. Educating senior management } \\
\text { 2. Taking time to understand the } \\
\text { individuals and existing culture } \\
\text { 3. Managing additional personal challenges }\end{array}$ \\
$\begin{array}{l}\text { Proactively managing } \\
\text { player acculturation }\end{array}$ & $\begin{array}{l}\text { 1. Informal processes } \\
\text { 2. Formal processes } \\
\text { (a) Recruitment }\end{array}$ \\
& (b) Onboarding \\
& (c) Well-being \\
\hline
\end{tabular}

enhance the trustworthiness and credibility of the results, namely, researcher reflexivity through the use of critical friends and member checking.

Given the researcher's previously mentioned partial insider status and his nuanced familiarity of themes being discussedthough this tacit knowledge is another strength of the study (Johnson, Martin, Rangikoepa Palmer, Watson, \& Ramsey, 2012) - there was a potential for an overreliance on that status when interpreting the data (McGannon, Smith, Kendellen, \& Gonsalves, 2019). However, through a process of reflexivity and the use of critical friends, this bias was mitigated. The role of critical friends was to listen to the researcher's interpretations, then offer critical feedback, challenging the construction of knowledge and helping to solidify the plausibility of the findings (Smith \& McGannon, 2018).

Transcriptions were also sent to the five participants to be member checked. Frequently used in qualitative research to validate data and control the subjective bias of the researcher (McGannon et al., 2019), the interview transcripts were e-mailed to the respective participants to confirm the accuracy of the data (Smith \& McGannon, 2018). No changes to the transcripts were made following this process.

\section{Results}

Through inductive analysis, two main themes emerged: (a) proactively managing personal acculturation and (b) proactively managing player acculturation. Findings revealed a number of factors pertaining to coach acculturation and the management of the acculturation environment.

\section{Proactively Managing Personal Acculturation}

When discussing personal acculturation experiences, the coaches revealed a number of principle approaches in proactively managing these processes. 
Educating senior management. For all coaches, an ongoing challenge was managing senior personnel, such as board members. For the participants, an important aspect of this management involved educating their senior counterparts.

As a Head Coach one of your biggest challenges is ensuring alignment across all facets of your program and the edges of the program with the stake holders and try to ensure that people are aware of what you're trying to produce and how you're trying to do it-and educating people on that process. (C4)

The people at the top of the organisation need to be able not just judge it on where you are in the table-but how else do they judge progress or development? I would be part of managing that. (C3)

In the second quote, Coach 3 challenged the thinking of his senior management to look beyond results and trophies, taking a more long-term view. All coaches specifically mentioned this as a challenge: "Development and winning at the same time is brilliant and everyone is happy, but you might need to manage upstairs ... I don't want to develop players, lose and then get the sack" (C5).

Taking time to understand the individuals and existing culture. Learning about the individuals within the team and understanding the existing team culture appeared to be an essential element for the coaches' personal acculturation strategies when moving into their current roles. First, across all coaching participants, there was an appreciation of the existing cultural diversity in their respective squads with this multicultural mix being seen as a strength, as Coach 1 described.

That diversity is a good thing for a playing group. We celebrate that-we don't want everyone to be the same. It's about understanding and celebrating each other's differences and showing them as a strength to the rest of the organisation.

Coach 2 shared a similar sentiment in embracing the uniqueness of each individual: "First and foremost we want people to be themselves." Building deep relationships with players was seen as a critical part of understanding the backgrounds of their multicultural teams with Coach 2 suggesting that it was the most important aspect: "I mean genuinely getting to know someone at as deeper level as you can ... more about who they are and what their backgrounds are." As the three following quotes, respectively, highlight, Coach 3 found it important to understand individual backgrounds to avoid potential racial stereotyping and develop a healthy understanding of different ethnic groups (i.e., ethnic attitudes), Coach 4 explained how a deeper understanding of his players helped manage positive performances, and Coach 3 Q15 went even further to connect with a player by meeting his family.

So, what does a Tongan culture look like? What's it like growing up in Tonga? Sharing that with the group. How different is that to growing up in Samoa or Fiji? We tend to be guilty of lumping them all in the same boat, don't we? (C3)

You need to understand how your players tick. I put a lot of emphasis around getting to know an individual playergetting to know their wife their girlfriend, their kids, their background and so on. Ultimately if they're happy at home we're going to get more out of them here. If they're in a position that they've got issues and they trust you and they know you care hopefully you can help them with their issue which hopefully makes them play better on a Saturday. (C4)
The biggest one is when a new player comes into the program we go and meet their family. The managers and coaches go and visit the village to thank them for their support ... . . We find that because the family support and community support is such a big thing here the player feels more confident when we've made that connection. (C3)

Developing these interpersonal skill sets would seem imperative for an incoming coach as well as applying that knowledge in the management of players, as Coach 5 commented.

You probably don't criticise Polynesians in front of other people because that's not their thing ... . You need to understand they're family orientated. Don't leave them isolated-if a Polynesian is on their own in a cold country, they won't play well for you and they'll be miserable. I've learnt that over time.

In addition to understanding the multicultural nature of their respective squads and building relationships with players, having an appreciation of previous team culture was also a fundamental consideration for the coaches as they acculturated into their new environment. All coaches reported using a period of time for observation and fact finding to ascertain what elements of the culture should remain and which aspects should be removed.

"Whatever It Takes" had been a slogan for the guys who have been here for seven, eight or nine years. It's been something that took them from second bottom in the comp to eventually winning a title. So that's a big part of the fabric, so for me to come and in and go, "I don't really like that" probably wouldn't have been well received. (C4)

Coach 3 was also acutely aware of his position as a foreigner and cautious of demanding certain expected behaviors that were the norm in his society of origin but perhaps less common in his current role.

In other teams you get inundated with kit and you have to wear particular kit at training and around the hotels but here there is a culture of being independent and wearing your own stuff at times-I've called it "village time" - they need to have this space away from what the demands of being a pro player all the time ... . Giving them some space at times, being in a hotel and saying right "Village Time" wear what you want I think has been an example of creating a positive response.

Coach 3 insisted on a number of performance behaviors but appeared to integrate these expectations with the cultural norms of the group. This would seem an important skill set within multicultural settings and particularly pertinent for a coach moving into a foreign environment, being especially conscious of the efficacy of enforcing previously held ideals from one cultural context to another.

As well as identifying what required change, an important appreciation was judging when to initiate changes. Coaches were conscious of "wielding the axe" too soon, suggesting a more gradual tack: "I was very mindful though of not being the know it all Englishman ... . Keep your powder dry for 100 days, meet the players, learn and ask good questions" (C1).

Managing additional personal challenges. The coaches also identified a number of additional personal challenges when moving into their current roles. First, two of the coaches found being away from their family particularly tough: "For me being away from 
family was our biggest challenge" (C4). Two of the coaches also acknowledged the challenges in modifying their preferred game strategy as a result of the climatic contrast between the northern and southern hemispheres, whereas Coach 3 experienced personal attacks:

One of the toughest things was potentially a bit of racismcoming to our country as a white man and you are assumed to have the same perceptions and opinions as every other white guy that's been there.

I had a letter handed to me up at a tournament by an eight year old who was running by —and I had my kids at the tournament as well-and the letter pretty much slagged me off and I was only here to take money off the local population and I should leave the country quickly.

\section{Proactively Managing Player Acculturation}

The strategy for integrating foreign players into the coaches' teams was managed through informal and formal processes.

Informal processes. For Coach 2, the informal processes included chats with players over lunch, and Coach 4 hosted a Christmas Day for players who were away from their families, affording them an opportunity to showcase their respective national cuisines.

So, an example would be a couple of Christmases ago ... we invited what we called the "orphans." So, anyone who didn't have a family here we hosted for Christmas - a couple of kiwis, a few Aussies, some Fijians and Tongan - and everyone had to bring a dish from their own culture. So we had all sorts! It was a banquet. I think all that sort of stuff allows players to show a bit of pride about where they're from.

Creating situations wherein players could come together was also imperative for Coach 3, who employed strategies that were perhaps best described as "formal-informal." Specific grouping of players at training, for example, encouraged rapport-building opportunities and more informal chats.

Formal processes. Player recruitment: There was great emphasis placed on "getting the right people on the bus" (C1) and, as a moderating factor prior to acculturation, ensuring that individuals were the right cultural fit for the team. Coaches' recruitment criteria were steered by an individual's character rather than talent with coaches strictly selecting players they could "trust" (C1) and who would "conform to the vision of the group" (C3), respectively. Taking such a steadfast recruitment stance is perhaps challenging for teams with slimmer talent pools, so perhaps a more robust recruitment process might be required wherein players are given opportunities to prove themselves. Coach 2 alluded to such a strategy.

We're a big believer that there's good in people ... and so what we try and do is meet potential new players together as a coaching group so it's not just me deciding whether I liked him or not in the spur of the moment ... we might meet them a couple of times or we might meet them with their wives or mum ... put them in a situation where you can judge them a little more.

This coordinated approach to player recruitment, in particular meeting with members of players' support network, is perhaps a useful strategy for coaches. Where talent is potentially at a premium in certain contexts, finding the appropriate judgment on what constitutes "good or bad" character seems to be an important consideration, and ongoing education ensuring that expectations are clear is another important implication, as Coach 2 stressed.

I've seen 18 or 19-year olds who are hard and difficult to deal with ... aged 27 they're magic. I think you've got be patient and you've got to educate.

Onboarding process: All five coaches reported meeting successfully recruited newcomers to outline the expectations within their environment, reminding them, "this is how we do things" (C2). Vital ongoing meetings with senior players ensured clarity by reemphasizing these nonnegotiable performance behaviors. In Coach 4's team, the player leadership group also played an important part, ensuring that younger players were clear about their roles and also linking foreign newcomers with established players from a similar cultural background.

We really drive our leaders to get a strong connection with the rest of the group so they understand if a youngster's struggling they'd grab them a go for a coffee and see how things are going - maybe they're lacking clarity in what we're trying to do- or it could be more of a cultural thing so we'd get one of our more experienced Fijian boys for example to help out with the new Fijian boy.

Well-being. Player well-being also emerged as key factor in the acculturation environment of the respective coaches. Coach 3 specifically focused on developing the whole person:

The program here is about improving individuals and it's an important we do because the connection we're making is rugby can do this for you and move you so far but you're going to move yourself beyond that and all your experiences that you're having here and your ability to self-mange and selfdetermine the next stage of your life will free you up to become the best player you can be here as well.

In referring to his holistic philosophy, the coach indicated how he not only prepared his athletes for the rigors of competition but simultaneously developed skill sets to prepare them for life in and away from rugby. In a critical link to performance, Coach 4 added, "If the guys you're dealing with know that you care about developing them as rugby players and their career and their life then they'd generally spill a bit of blood for you."

\section{Discussion}

In response to the first research question regarding elite coaches' personal acculturation strategies, results revealed the initial step of gaining a rich understanding of their players' lives and history, particularly their ethnic background. In doing so, the coaches demonstrated the importance of attempting to appreciate the individuals within the "society of settlement" (Berry, 1997)—or perhaps, in this context, "team" of settlement-thus helping coaches to inform their practices accordingly. This gathering of information can also occur prior to starting and can help facilitate the coaches' cultural transition (Ryba, Stambulova, \& Ronkainen, 2016). Striking relationships with key stakeholders, specifically senior management, also proved an important aspect of coach acculturation, and in educating these groups as to the balance between long-term development and immediate success, the coaches' hoped to help secure the longevity of their tenure and 
subsequent ability to execute team goals. The role of coaches handling senior managerial officials while attempting to drive an effective environment has been previously highlighted by English, Nash, and Martindale (2020), who revealed challenges such as disconnected agendas, interfering administrators, and distrust of board members within the development environment of South African Cricket. Gaining an understanding of the team's cultural landscape and the staged approach to executing any required change was another key aspect of the coaches' acculturation process and evidence of best practice within cultural change (Cruickshank \& Collins, 2015; Cruickshank, Collins, \& Minten, 2014).

Concerning the second research question regarding the personal challenges experienced by the acculturating coaches, they reported feelings of separation that are common stressors in immigrant coaches' experiences (Schinke et al., 2011) and highlight the types of family challenges previously shown to be prevalent in elite coaching (Borges et al., 2015; Felber Charbonneau, Camiré, \& Lemyre, 2020; Joncheray, Burlot, \& Julla-Marcy, 2019). For coaches moving to new roles overseas, having coping strategies in place to maintain professional and family life balance are invaluable. The personal attacks experienced by Coach 3 , in stark contrast to the friendly welcoming of Russian gymnastic coaches in New Zealand (Kerr \& Obel, 2018), potentially indicate a degree of cultural blindness from the hosts expressed through racial stereotyping (Schinke et al., 2011). In helping to promote a more positive perception of an incoming coach and as an important moderating factor during and potentially before the acculturation process, Cruickshank et al (2014) suggested adopting an inclusive management strategy and gathering support from within the organization, such as existing staff, as well as managing key external allies and the messages sent to the wider community. These public relation behaviors as part of an elite coach's role (Rynne \& Mallett, 2012) would help foster more positive attitudes and social support within the new society of settlement (Berry, 1997).

Finally, regarding the need to deepen the understanding of how the hosts support incoming players, the respective coaches' acculturation environments were examined, and a number of salient factors emerged. For instance, each of the coaches' diverse teams reinforced the positive approach to cultural pluralism adopted by their respective society (or team) of settlement and indicated a positive multicultural ideology (Berry \& Kalin, 1995). Allowing players to be themselves may have also fostered more creative and effective working behaviors (Allende, 2018). Typical of high-performance environments, however, there were also explicit expectations regarding performance behaviors, ensuring that all players, irrespective of their background and culture, were held accountable for and aligned to the same standards (Schinke \& McGannon, 2014). In the elite sport context, therefore, it might be appropriate to add "expected performance behaviors" as an additional element to Berry's (1997) society of settlement level. At least one of the coaches, through his "village time," adopted a more culturally informed leadership approach and evidently understood the cultural context of his society of settlement and with it the implicit expectations of the group he coached. He, therefore, altered his way of operating and demonstrated an important skill set within multicultural settings (Duchesne, Bloom, \& Sabiston, 2011).

Informal and formal acculturation strategies were also important aspects to each of the coaches' respective environments. The Christmas gathering hosted by one of the coaches, for example, may have mitigated the potential feelings of isolation with the foreign players being away from their families-a common stress for relocating athletes (Schinke et al., 2011 - as well as potentially influencing the social bonds between team mates, a proven factor leading to greater team cohesion (Khomutova, 2016). It is also a reminder for coaches to focus on the acculturation experiences of individuals in and away from the training environment (Schinke et al., 2017). A similar shared approach was reported in some National Hockey League and Major League Baseball franchises, which rotated various national dishes of their team members in the player clubhouse (Battochio et al., 2013).

Creating shared acculturation practices, such as "buddy systems," was an example of a formal strategy employed in this research. This type of practice was previously demonstrated among professional National Hockey League players who were paired with players of similar shared experiences and cultural backgrounds, which was an essential factor in the newcomer gaining a sense of belonging (Battochio et al., 2013). Other formal strategies included onboarding meetings with coaches and senior players, which are examples of the social support as part of the moderating factors during acculturation that can augment the engagement of newcomers and provide a platform for peak performance (Ryba et al., 2018). The scrutiny with which coaches carried out their decisions on contracting a player was another key aspect of the acculturation environment. Not only did coaches access the wider network of players (i.e., family members) to help inform recruitment, the decisions were also greatly dependent on a player's character. The use of networks as a useful tool in the recruitment process has been previously highlighted (Borges et al., 2015 ) with selection based on character commonplace in New Zealand, for example, where coaches often seek "good buggers" over skill sets (Hassanin, Light, \& Macfarlane, 2018). As revealed in the results, for teams with slimmer talent pickings, this may prove to be a particular challenge if a player were poor in character but rich in talent-short-term results at the price of long-term team cohesion (Leggat, Smith, \& Figgins, 2018).

Finally, the world of elite sport can often be hostile and unpleasant, and although success can be achieved under such conditions (Cruickshank \& Collins, 2015), there has been a more recent shift to promote high performance and well-being (Brown \& Arnold, 2019), further evidenced in this research. Integrating wellbeing strategies was part of the coaches' acculturation environments and a vital aspect of a high-performance coach's role (Rynne \& Mallett, 2012), with specific examples of developing their players holistically in a familiar approach to other elite sport settings (Lee \& Price, 2016) and emerging nations (Hall, Jones, \& Martindale, 2019). Coaches talked of caring for their players, too, and in a multicultural context where players might experience acculturative stress, there may be a need to keep a close eye on player well-being, ensuring that stress levels are managed and reducing the impact of demotivation, burnout, and poor performance, for example. This is perhaps another example where Berry's (1997) framework could be modified for elite sport contexts and differentiate "well-being" as a moderating factor during acculturation.

\section{Conclusion}

This article examined five elite rugby union coaches, their personal acculturation experiences, and how they managed their respective acculturation environments. Although it represents a small sample size in a specific context, a number of theoretical and applied implications emerged. 


\section{Theoretical Implications}

Berry's (1997) framework has been uniquely utilized in this research as a lens to view the acculturation experiences of elite coaches and the management of their respective acculturation environments. Many factors emerged that substantiated previous "generic" knowledge regarding how coaches lead and manage high-performance teams. However, what has also been presented, and subsequently has driven the theory forward, are the mechanisms and nuances of effectively creating and managing a highperformance team within diverse/multicultural groups as well as the adaptive leadership practices required to navigate this, maximizing buy-in across the group. Furthermore, in a similar way to Rynne and Mallett (2012), several modifications to Berry's (1997) original framework might be considered to provide a best fit for this sample and for future exploration within elite sport contexts. These include contextualizing group factor terms in elite sport, such as "team" of settlement, and adding specific moderating variables, such as player education and holistic development (factors during acculturation), as well as prior coaching/playing experience of the incoming individual (factors prior to acculturation). Finally, it might also be pertinent within an elite sport context to explicitly recognize "performance outcome" as a key feature of adaptation.

\section{Applied Implications}

Several applied implications transpired from the research. First, as a foreign coach there may be a need to prepare for and manage potential antipathy from members within the society of settlement, Q27 particularly if the coach is seen to be taking "one of the local's jobs" or enforcing change. An appreciation of when to execute these changes has been shown to be critical. Then, while importantly driving key performance behaviors, an appreciation of the cultural expectations within the environment of settlement and an appropriate balance of well-being is noteworthy.

Second, fostering relationships with players and key stakeholders is a crucial consideration for coaches in this context as well as the management of new foreign players into the acculturation environment. Adopting a shared acculturation approach is favorable and may help individuals in positively acculturating and, ultimately, performing. Further relationship building with internal stakeholders, such ambitious senior management, and external stakeholders, such as the media, may also prove useful for managing expectations and positively managing external messages, respectively.

Finally, it appears that player recruitment decisions must be as robust as possible to avoid nonselection of high-quality but potentially problematic players who, under the right circumstances, could develop and adapt their behavior to fit the culture. As identified, creating innovative and flexible talent identification and selection processes as well as accessing "typical" references from former coaches and/or players may provide a broader view of whether a player is a good "cultural fit."

\section{Study Limitations and Future Research}

Notwithstanding the strengths of the research, there are some Q29 limitations that are important to recognize. First, although the focus of the research was intentionally aimed at elite coach acculturation and their management of the acculturation environment, other relevant opinions (e.g., players' experience) are missing, thus cross examination of these coaches' experiences with therefore, wish to consider a more holistic representation of a sporting environment that includes player, assistant coach, support staff, and senior management opinion. Second, with four out of the five coaches based in the U.K. coaching 15-a-side male teams, the this context dominated the research. Furthermore, only four out of five coaches had experienced acculturation challenges in their current role. Future research, therefore, may wish to consider a broader spread of coaches from the top leagues across the world and, although not revealed in the results, examine coaches with multiple acculturation experiences including, for example, the potential challenge of learning a new language as part of the acculturation process. In addition, a wider selection of seven-aside coaches as well as work within other sport contexts may be explored. Finally, it might be argued that findings may only be transferable to other male-led, high-performance rugby environments with subsequent caution in generalizing findings across sporting milieus.

\section{References}

Allende, S.C. (2018). Be more pirate. Portfolio: Penguin.

Battochio, R.C., Schinke, R.J., McGannon, K.R., Tenenbaum, G., Yukelson, D., \& Crowder, T. (2013). Understanding immigrated professional athletes' support networks during post-relocation adaptation through media data. International Journal of Sport and Exercise Psychology, 11(1), 101-116. doi:10.1080/1612197X.2013.748996

Berry, J.W. (1997). Lead article immigration, acculturation, and adaptation. Applied Psychology: An International Review, 46(1), 5-68.

Berry, J.W. (2005). Acculturation: Living successfully in two cultures. International Journal of Intercultural Relations, 29(6):697-712. doi:10.1016/j.ijintrel.2005.07.013

Berry, J.W., \& Kalin, R. (1995). Multicultural and ethnic attitudes in Canada: An overview of the 1991 national survey. Canadian Journal of Behavioural Science, 27(3), 301.

Borges, M., Rosado, A., de Oliveira, R., \& Freitas, F. (2015). Coaches' migration: A qualitative analysis of recruitment, motivations and experiences. Leisure Studies, 34(5), 588-602. doi:10.1080/02614367. 2014.939988

Braun, V., \& Clarke, V. (2006). Using thematic analysis in psychology. Qualitative Research in Psychology, 3(2), 77-101. doi:10.1191/ 1478088706qp063oa

Braun, V., \& Clarke, V. (2019). Reflecting on reflexive thematic analysis. Qualitative Research in Sport, Exercise and Health, 11(4), 589-597. doi:10.1080/2159676X.2019.1628806

Brown, D.J., \& Arnold, R. (2019). Sports performers' perspectives on facilitating thriving in professional rugby contexts. Psychology of Sport and Exercise, 40, 71-81. doi:10.1016/j.psychsport.2018.09.008

Chirkov, V. (2009). Critical psychology of acculturation: What do we study and how do we study it, when we investigate acculturation? International Journal of Intercultural Relations, 33, 94-105. doi:10. 1016/j.ijintrel.2008.12.004

Cote, J., Salmela, J.H., Baria, A., \& Russell, S.J. (1993). Organizing and interpreting unstructured qualitative data. The Sport Psychologist, $7(2), 127-137$.

Creswell, J.W., Hanson, W.E., Clark Plano, V.L., \& Morales, A. (2007). Qualitative research designs: Selection and implementation. The Counseling Psychologist, 35(2), 236-264. doi:10.1177/001100 0006287390

Cruickshank, A., \& Collins, D. (2015). Illuminating and applying "the dark side:" Insights from elite team leaders. Journal of Applied Sport Psychology, 27(3), 249-267. doi:10.1080/10413200.2014.982771 
Cruickshank, A., Collins, D., \& Minten, S. (2014). Driving and sustaining culture change in Olympic sport performance teams: A first exploration and grounded theory. Journal of Sport and Exercise Psychology, 36(1), 107-120. PubMed ID: 24501148 doi:10.1123/jsep.2013-0133

Duchesne, C., Bloom, G.A., \& Sabiston, C.M. (2011). Intercollegiate coaches' experiences with elite international athletes in an American sport context. International Journal of Coaching Science, 5(2), 49-68.

Earley, P.C., \& Ang, S. (2003). Cultural intelligence: Individual interactions across cultures. Stanford University Press.

English, C., Nash, C., \& Martindale, R. (2020). Exploring the coachadministrator relationship within the SA cricket development environment. European Sport Management Quarterly. Advance online publication. doi:10.1080/16184742.2020.1749689

Felber Charbonneau, E., Camiré, M., \& Lemyre, P.-N. (2020). Motives for and experiences of expatriation to coach. International Sport Coaching Journal, 2014, 1-8. doi:10.1123/iscj.2019-0079

Giacobbi, P.R., Poczwardowski, A., \& Hager, P. (2005). A pragmatic research philosophy for sport and exercise psychology. The Sport Psychologist, 19(1), 18-31. doi:10.1123/tsp.19.1.18

Hall, A.J.A., Jones, L., \& Martindale, R.J.J. (2019). The talent development environment questionnaire as a tool to drive excellence in elite sport environments. International Sport Coaching Journal, 6(2), 187-198. doi:10.1123/iscj.2018-0041

Hassanin, R., Light, R.L., \& Macfarlane, A. (2018). Developing 'good buggers': Global implications of the influence of culture on New Zealand club rugby coaches' beliefs and practice. Sport in Society, 21(8), 1223-1235. doi:10.1080/17430437.2018.1443598

Johnson, T., Martin, A.J., Rangikoepa Palmer, F., Watson, G., \& Ramsey, P.L. (2012). Collective leadership a case study of the all blacks. AsiaPacific Management and Business Application, 1, 53-67. Retrieved from http://apmba.ub.ac.id

Joncheray, H., Burlot, F., \& Julla-Marcy, M. (2019). Is the game lost in advance? Being a high-performance coach and preserving family life. International Journal of Sports Science and Coaching, 14(4), 453462. doi:10.1177/1747954119860223

Kerr, R., \& Moore, K. (2015). Hard work or child's play? Migrant coaches' reflections on coaching gymnastics in New Zealand. World Leisure Journal, 57(3), 185-195. doi:10.1080/16078055.2015.1066601

Kerr, R., \& Obel, C. (2018). The migration of gymnastics coaches from the Former Soviet Union to New Zealand: An actor-network theory perspective. Leisure Studies, 37(5), 615-627. doi:10.1080/02614367. 2018.1482367

Khomutova, A. (2016). Basketball coaches' experience in working with multicultural teams: Central and Northern European perspectives. Sport in Society, 19, 861-876. doi:10.1080/17430437.2015.1067777

Lee, J., \& Price, N. (2016). A national sports institute as a learning culture. Physical Education and Sport Pedagogy, 21, 10-23. doi:10.1080/ 17408989.2015.1072507

Leggat, F.J., Smith, M.J., \& Figgins, S.G. (2018). Talented but disruptive: An exploration of problematic players in sports teams. Journal of Applied Sport Psychology. 32, 357-376. doi:10.1080/10413200. 2018.1549621

McGannon, K.R., Smith, B., Kendellen, K., \& Gonsalves, C.A. (2019). Qualitative research in six sport and exercise psychology journals between 2010 and 2017: An updated and expanded review of trends and interpretations. International Journal of Sport and Exercise Psychology. Advance online publication. doi:10.1080/1612197X. 2019.1655779

Meisterjahn, R.J. (2011). "Everything was different": An existential phenomenological investigation of US professional basketball players' experiences overseas.
Moser, A., \& Korstjens, I. (2018). Series: Practical guidance to qualitative research. Part 3: Sampling, data collection and analysis. European Journal of General Practice, 24(1), 9-18. doi:10.1080/13814788. 2017.1375091

Orlowski, J., Wicker, P., \& Breuer, C. (2016). Determinants of labour migration of elite sport coaches. European Journal of Sport Science, 16(6), 711-718. PubMed ID: 26744912 doi:10.1080/17461391. 2015.1130751

Ronkainen, N.J., Khomutova, A., \& Ryba, T.V. (2019). "If my family is okay, I'm okay": Exploring relational processes of cultural transition. International Journal of Sport and Exercise Psychology, 17(5), 493508. doi:10.1080/1612197X.2017.1390485

Ryba, T.V., Schinke, R.J., Stambulova, N.B., \& Elbe, A.M. (2018). ISSP position stand: Transnationalism, mobility, and acculturation in and through sport. International Journal of Sport and Exercise Psychology. doi:10.1080/1612197X.2017.1280836

Ryba, T.V., Stambulova, N.B., \& Ronkainen, N.J. (2016). The work of cultural transition: An emerging model. Frontiers in Psychology, 7, 427. doi:10.3389/fpsyg.2016.00427

Ryba, T.V., Stambulova, N.B., Ronkainen, N.J., Bundgaard, J., \& Selänne, H. (2015). Dual career pathways of transnational athletes. Psychology of Sport and Exercise, 21, 125-134. doi:10.1016/j.psychsport.2014. 06.002

Rynne, S.B., \& Mallett, C.J. (2012). Understanding the work and learning of high performance coaches. Physical Education and Sport Pedagogy, 17(5), 507-523. doi:10.1080/17408989.2011.621119

Schinke, R.J., Blodgett, A.T., McGannon, K.R., \& Ge, Y. (2016a). Finding one's footing on foreign soil: A composite vignette of elite athlete acculturation. Psychology of Sport and Exercise, 25, 36-43. doi:10. 1016/j.psychsport.2016.04.001

Schinke, R.J., Blodgett, A.T., McGannon, K.R., Ge, Y., Oghene, O., \& Seanor, M. (2016b). A Composite vignette on striving to become "someone" in my new sport system: The critical acculturation of immigrant athletes. The Sport Psychologist, 30, 350-360. doi:10. 1123/tsp.2015-0126

Schinke, R.J., Blodgett, A.T., McGannon, K.R., Ge, Y., Oghene, O., \& Seanor, M. (2017). Adjusting to the receiving country outside the sport environment: A composite vignette of Canadian immigrant amateur elite athlete acculturation. Journal of Applied Sport Psychology, 29, 270-284. doi:10.1080/10413200.2016.1243593

Schinke, R.J., \& McGannon, K.R. (2014). The acculturation experiences of (and with) immigrant athletes. International Journal of Sport and Exercise Psychology, 12, 64-75. doi:10.1080/1612197X.2013. 785093

Schinke, R.J., McGannon, K.R., Battochio, R.C., \& Wells, G.D. (2013). Acculturation in elite sport: A thematic analysis of immigrant athletes and coaches. Journal of Sports Sciences, 31(15), 1676-1686, doi:10. 1080/02640414.2013.794949

Schinke, R.J., McGannon, K.R., \& Smith, B. (2016c). Routledge international handbook of sport psychology. Routledge.

Schinke, R.J., McGannon, K.R., Yukelson, D., Cummings, J., \& Parro, W. (2015). Helping with the acculturation of immigrant elite coaches in Canadian sport contexts. Journal of Sport Psychology in Action, 6, 17-27. doi:10.1080/21520704.2014.981325

Schinke, R.J., Yukelson, D., Bartolacci, G., Battochio, R.C., \& Johnstone, K. (2011). The challenges encountered by immigrated elite athletes. Journal of Sport Psychology in Action, 2, 10-20. doi:10.1080/ 21520704.2011.556179

Schwartz, S.J., Unger, J.B., Zamboanga, B.L., \& Szapocznik, J. (2010). Rethinking the concept of acculturation: Implications for theory and research. American Psychologist, 65(4), 237-251. doi:10.1037/ a0019330 
Smith, B., \& McGannon, K.R. (2018). Developing rigor in qualitative research: Problems and opportunities within sport and exercise psychology. International Review of Sport and Exercise Psychology, 11, 101-121. doi:10.1080/1750984X.2017.1317357

Tao, Y.C., Rynne, S.B., \& Mallett, C.J. (2019). Blending and becoming: Migrant Chinese high-performance coaches' learning journey in Australia. Physical Education and Sport Pedagogy, 24(6), 582597. doi:10.1080/17408989.2019.1641191

Verkuyten, M. (2005). Immigration discourses and their impact on multiculturalism: A discursive and experimental study. British Journal of Social Psychology, 44(2), 223-240.
Ward, C., \& Kus, L. (2012). Back to and beyond Berry's basics: The conceptualization, operationalization and classification of acculturation. International Journal of Intercultural Relations, 36(4), 472485. doi:10.1016/j.ijintrel.2012.02.002

Weller, S. (2017). Using Internet video calls in qualitative (longitudinal) interviews: Some implications for rapport. International Journal of Social Research Methodology, 20(6), 613-625. doi:10.1080/ 13645579.2016.1269505 